\title{
Support Materials and Characterization Tools for Nanostructured Catalysts
}

\author{
K.P. de Jong ${ }^{1}$ \\ 1 Inorganic Chemistry and Catalysis, Department of Chemistry, Utrecht University \\ P.O. Box 80083, 3508 TB Utrecht - The Netherlands \\ e-mail: k.p.dejong@chem.uu.nl
}

Résumé - Matériaux de support et outils de caractérisation des catalyseurs nanostructurés Les matériaux de support nanostructurés considérés dans ce travail permettent de faciliter la recherche fondamentale en catalyse hétérogène. Des cas d'étude sont présentés, en particulier des catalyseurs d'hydrogénation à base de métaux supportés sur des nanofibres de carbone. La tomographie électronique s'avère être un outil de caractérisation important pour l'imagerie en trois dimensions de catalyseurs nanostructurés, avec une résolution nanométrique.

Abstract - Support Materials and Characterization Tools for Nanostructured Catalysts Nanostructured support materials are considered in this work as a means to facilitate fundamental research in heterogeneous catalysis. Case studies are presented, in particular carbon nanofiber supported metal catalysts for hydrogenation catalysis. Electron tomography is shown to be an important characterization tool to image nanostructured catalyst in three dimensions with nanometer resolution. 


\section{NANOSTRUCTURED SUPPORT MATERIALS}

Nanostructured support materials [1, 2] hold great potential for the development of supported catalysts with unsurpassed performance. In comparing a conventional silica support (silica gel) with an ordered mesoporous silica (MCM-41), it is noted that at the atomic scale both materials consist of amorphous silica. At the mesoscopic scale the extent of ordering is strikingly different as can be concluded from the transmission electron microscopy (TEM) images in Figure 1.

With silica gel and many other conventional support materials the pore system consist of the open space between primary particles. The random packing of primary particles leads to an ill-defined pore system. Since catalyst preparation from aqueous precursor solutions depends critically on the pore system, one may anticipate an inhomogeneous distribution of the active component over the support material. Moreover, the complexity of the porous material hampers detailed characterization by techniques such as electron microscopy and nitrogen physisorption.

Probably the most influential and most studied nanostructured oxidic support materials are the ordered mesoporous materials $[3,4]$ such as MCM-41. In these materials the pore system has developed as an integral part of the synthesis. In fact, the structural directing agents used during synthesis largely determine the final pore system that develops upon calcination. In the case of MCM-41 the one-dimensional pores display a diameter of about $3 \mathrm{~nm}$ while the pore wall thickness amounts to $1 \mathrm{~nm}$, which leads to specific surface areas of about $1000 \mathrm{~m}^{2} \cdot \mathrm{g}^{-1}$. These specific surface areas cannot be realized with conventional mesoporous supports. The uniformity of the pores is expected to be beneficial for catalysts preparation involving impregnation and drying techniques.
A second class of nanostructured support materials involves carbon materials. Up till now the most widely used carbon support materials in catalysis comprise activated carbons from natural origin. With respect to the structure of these materials comments are relevant similar to those about silica gel (vide supra). Furthermore, the control over the chemical composition, nature of the (micro-)pores and the mechanical properties of the macroscopic bodies is limited. More recently, the use of nanostructured carbon materials, in particular carbon nanofibers and carbon nanotubes, has been considered [5-8]. A typical example of these materials is shown in Figure 2.

The fiber diameter ranges from $20-40 \mathrm{~nm}$ leading to specific surface areas of $100-200 \mathrm{~m}^{2} \cdot \mathrm{g}^{-1}$. The strongly interwoven nature of these materials leads to macroscopic particles with sizes of $0.5-1.0 \mathrm{~mm}$ of appreciable mechanical strength. In the literature discussions about the mechanical properties of these materials have been confusing with some groups referring to nanostructured supports as "fluffy and mechanically weak" and other groups as "highly dense and mechanically strong". However, the differences in synthesis conditions and nickel-based growth catalyst used had a determining influence on the properties of the final product. Most recently, we have published a paper [9] that indicated the key parameters to arrive at dense carbon nanofiber bodies. A high density of nickel particles of well-defined size and relatively slow growth from an inert carbon precursor $\left(\mathrm{CO}\right.$ or $\left.\mathrm{CH}_{4}\right)$ are key aspects to obtain CNF particles of high bulk density $\left(>0.8 \mathrm{~g} \cdot \mathrm{ml}^{-1}\right)$ and high bulk crushing strength $(\mathrm{BCS}>1 \mathrm{MPa})$.

We note that several other approaches have been followed to arrive at structured carbons. In particular we note the work of the group of Su and Schlögl [10-12], the group of Muhler $[13,14]$ and the group of Lefferts [15].
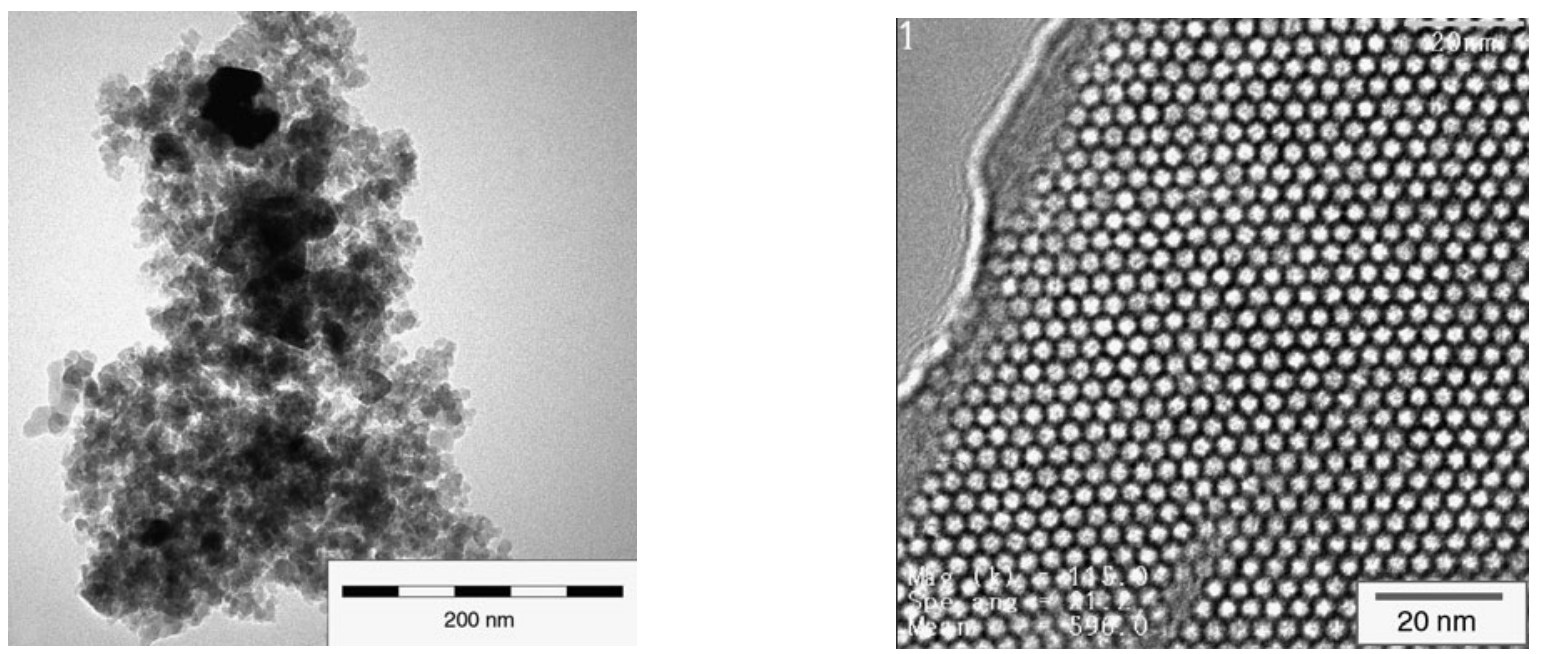

Figure 1

TEM images of silica gel (left) and MCM-41 (right). 

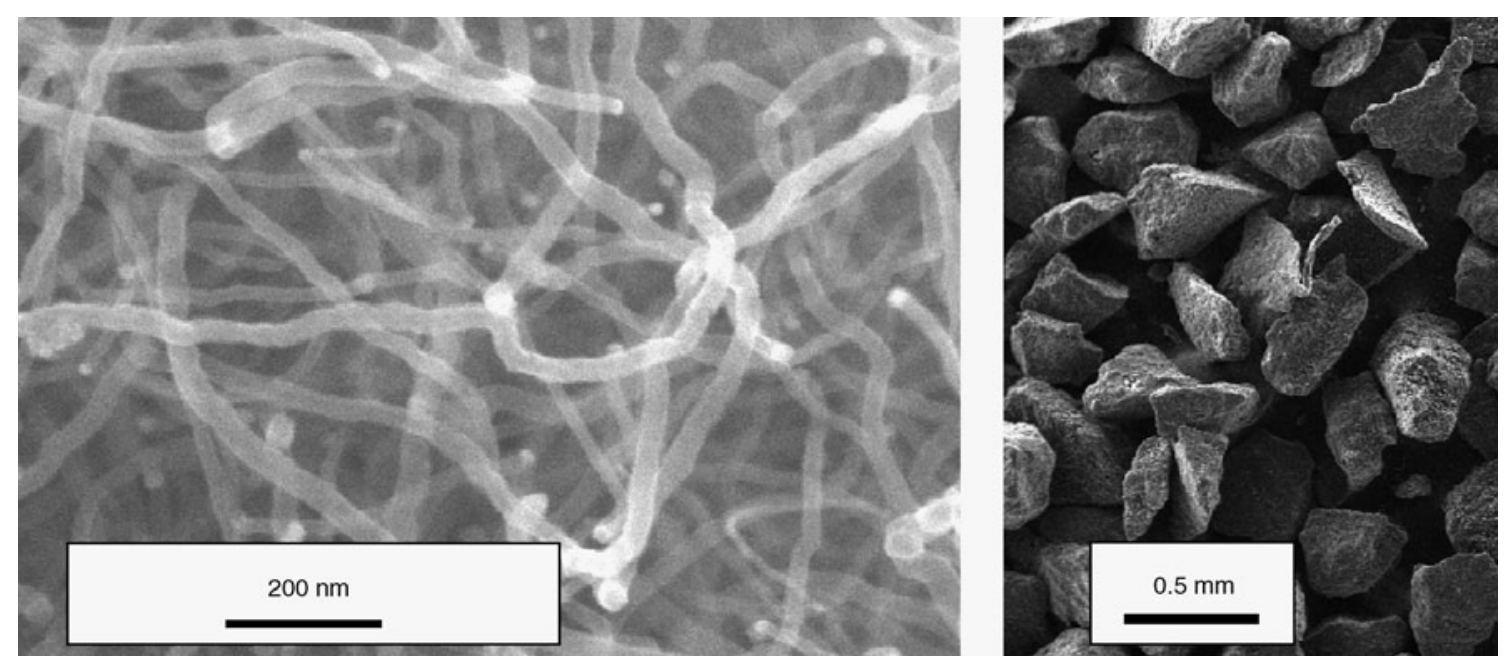

Figure 2

Carbon nanofiber support material. SEM images at medium resolution (left) and low resolution showing particles of 0.5-1.0 mm (right).

Hereafter we present case studies of the use of carbon nanofiber (CNF) support material for fundamental research in catalysis. One of the key challenges, however, is the preparation of supported metal (oxide) catalysts based on this support. Starting from studies on the preparation (Section 2.1), we continue with platinum catalysts used for cinnamaldehyde hydrogenation (Section 2.2) and a summary of other studies using CNF supports (Section 2.3).

\section{CARBON NANOFIBER SUPPORTED CATALYSTS}

\subsection{Preparation of Supported Metal Catalysts}

Since the chemical nature of the carbon nanofibers comprises graphite-like carbon the extent of interaction with precursors from aqueous solutions will be limited if any. To enhance this interaction surface oxidation of CNF has been used [16]. The types of the oxygen-containing groups thus obtained are indicated schematically in Figure 3.

The first and very important role of these groups is to switch the surface properties from hydrophobic to hydrophilic. This allows impregnation and drying techniques from aqueous solutions to be used for the preparation of supported catalysts. Deposition precipitation from diluted suspensions of the $\mathrm{CNF}$ in an aqueous solution of the metal precursor can also be used. The latter methodology has been studied extensively for nickel using urea-based deposition precipitation [17]. The chemistry involved reads:

$$
\begin{gathered}
\mathrm{CO}\left(\mathrm{NH}_{2}\right)_{2}+3 \mathrm{H}_{2} \mathrm{O} \rightarrow \mathrm{CO}_{2}+2 \mathrm{NH}_{4}^{+}+2 \mathrm{OH}^{-} \\
\mathrm{Ni}^{2+}+2 \mathrm{OH}^{-} \rightarrow \mathrm{Ni}(\mathrm{OH})_{2}
\end{gathered}
$$

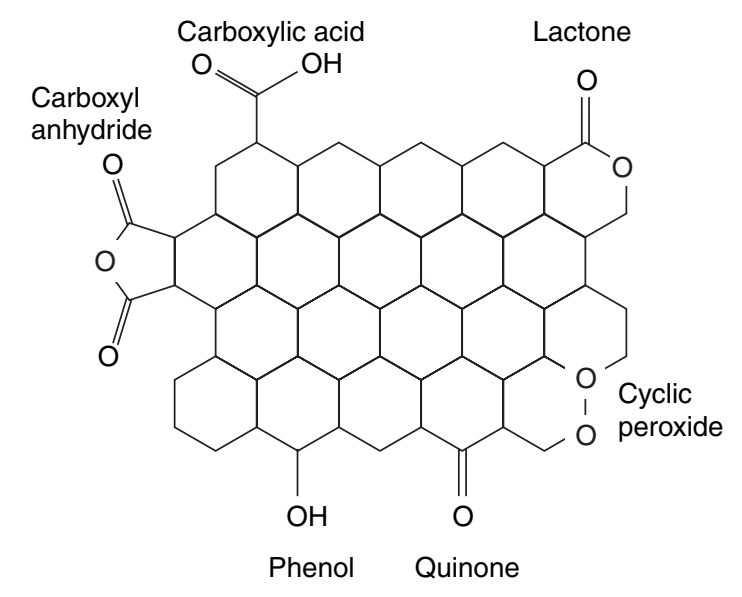

Figure 3

Schematic representation of different oxygen-containing groups on a surface-oxidized graphitic carbon.

At first glance this looks familiar as this chemistry has been extensively used and studied with silica supports. With silica, the extensive work by Louis and co-workers $[18,19]$ has proven that a mixed compound of support and metal hydroxide is formed under most circumstances. This mixed compound displays a lower solubility of nickel than bulk nickel hydroxide thus providing a thermodynamic driving force for selective precipitation onto the oxidic support material. For a carbon-based support this thermodynamic driving force does not exist as the formation of a mixed compound of nickel hydroxide and graphitic carbon is not possible. From a detailed study it has occurred that nickel-ion adsorption has 
to occur to favor nucleation of the nickel hydroxide on the carbon support. Nickel-ion adsorption under the prevailing conditions calls for acidic groups, in particular carboxylic acid groups. In the case of phenol-type groups nickel-ion adsorption is too weak or too limited to assist nucleation of the new phase on the support [17].

Typical results of deposition precipitation of nickel hydroxide are shown in Figure 4. After precipitation the platelets of nickel hydroxide have been bonded to the carbon nanofiber through their edge or basal planes. After reduction in hydrogen followed by air passivation, spherical nickel particles $(6-8 \mathrm{~nm})$ uniformly distributed over the carbon nanofibers were obtained.

For nickel the metal loading has been varied between 10 and $50 \mathrm{wt} \%$ using deposition precipitation [20].

Excellent results with deposition precipitation have been obtained with ruthenium and platinum too [21]. For Pt, however, ion adsorption prevailed over formation of a new hydroxide phase thus limiting the metal loading to 3-5 wt $\%$.

\subsection{Platinum Catalysts for Hydrogenation of Cinnamaldehyde}

Deposition onto surface-oxidized carbon nanofiber of platinum (3.6 wt $\%$ ) was carried out using deposition precipitation. Following reduction at $473 \mathrm{~K}$ the samples have been heated at different temperatures in nitrogen to remove part of the oxygen-containing groups from the CNF surface. The resulting platinum metal particle size has been determined from hydrogen chemisorption, TEM and EXAFS. The results are shown in Table 1. Clearly, platinum particles of $\sim 1 \mathrm{~nm}$ have been obtained after reduction and subsequent thermal treatment at temperatures not exceeding $773 \mathrm{~K}$. After treatment in nitrogen at $973 \mathrm{~K}$ some sintering of Pt was apparent (Fig. 5 and Table 1). The samples of $\mathrm{Pt} / \mathrm{CNF}$ thus obtained were investigated in a slurry reactor for the hydrogenation of cinnamaldehyde at $383 \mathrm{~K}, 50$ bar and isopropanol as solvent.

TABLE 1

Metal particle sizes from different techniques of $\mathrm{Pt} / \mathrm{CNF}$ heated at different temperatures.

\begin{tabular}{c|c|c|c|c}
\hline $\begin{array}{c}\text { Heat treatment } \\
\text { in } \mathrm{N}_{2}(\mathrm{~K})\end{array}$ & $\begin{array}{c}\mathrm{H} / \mathrm{Pt} \text {, total } \\
\text { (at/at) }\end{array}$ & $\begin{array}{c}\mathrm{d}_{\mathrm{H} 2} \\
(\mathrm{~nm})\end{array}$ & $\begin{array}{c}\mathrm{d}_{\mathrm{TEM}} \\
(\mathrm{nm})\end{array}$ & $\begin{array}{c}\mathrm{d}_{\text {EXAFS }} \\
(\mathrm{nm})\end{array}$ \\
\hline- & 0.81 & 1.4 & $<1-2$ & 1.0 \\
573 & 1.08 & 1.0 & $<1-2$ & \\
773 & 0.76 & 1.5 & $<1-2$ & 1.0 \\
973 & 0.50 & 2.3 & $<1-3$ & \\
\hline
\end{tabular}

The overall activity for the hydrogenation of cinnamaldehyde was obtained and has been plotted as a function of the pretreatment temperature in Figure 6. A tremendous increase of gross activity - up to a factor of 25 - of Pt/CNF with pretreatment temperature was apparent from the results shown. From a detailed kinetic and diffusion analysis [22] it has appeared that the intrinsic activity enhancement was even much larger as the most active catalysts suffered from diffusion limitation under the selected experimental conditions.
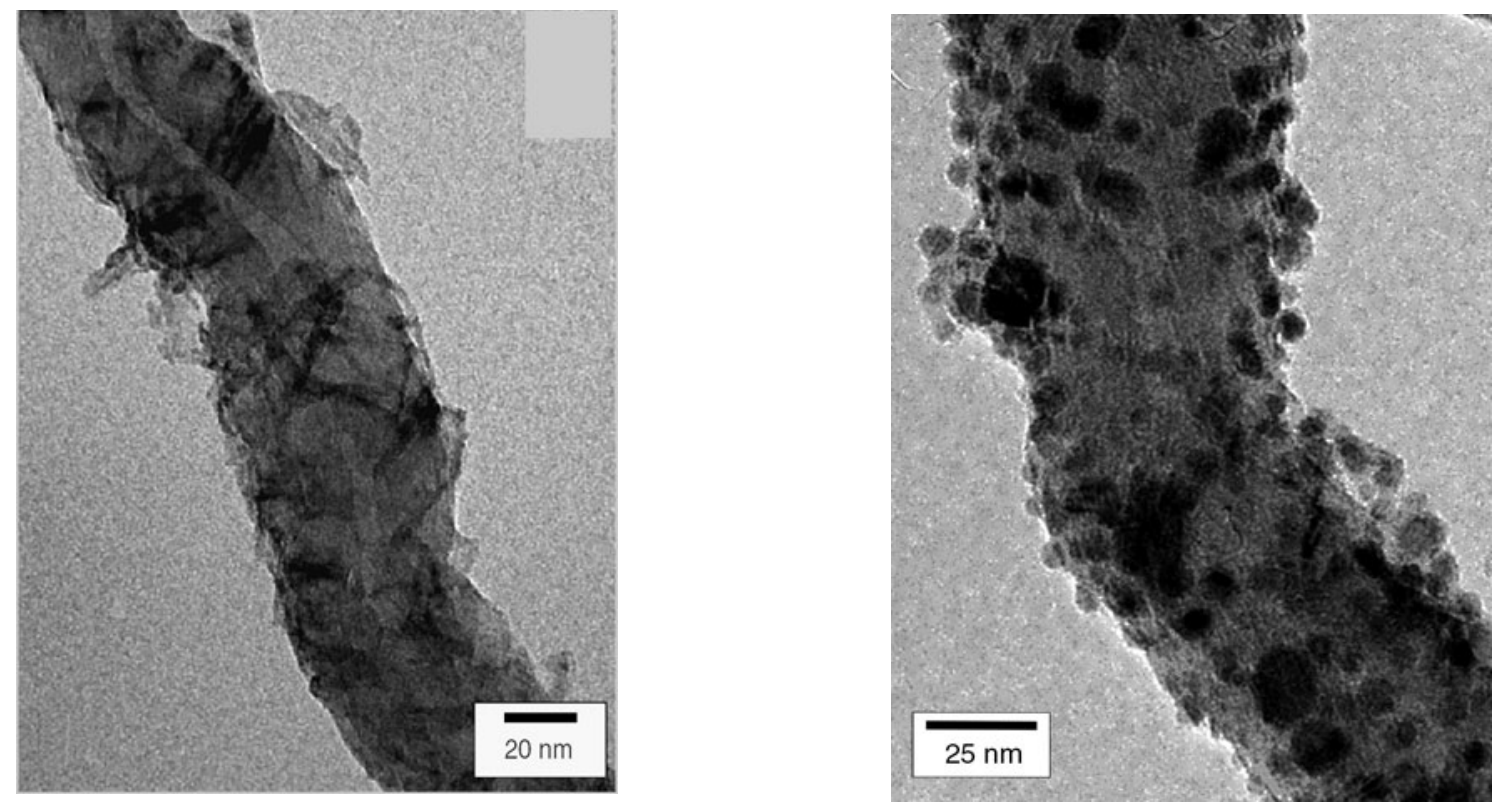

Figure 4

TEM images of dried nickel hydroxide (left) and reduced metallic nickel (right) on a carbon nanofiber (loading $10 \mathrm{wt} \% \mathrm{Ni}$ ). 

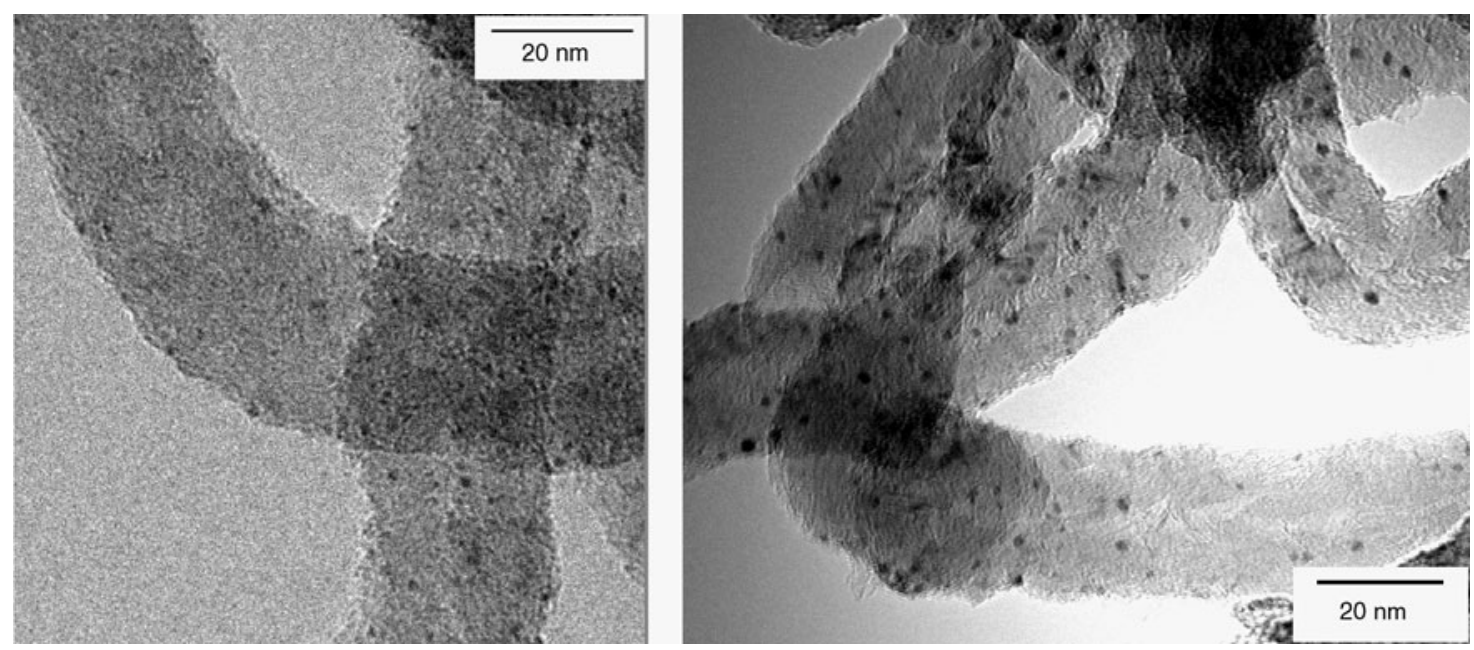

Figure 5

TEM images of Pt/CNF after reduction at $473 \mathrm{~K}$ (left) and subsequent thermal pretreatment at $973 \mathrm{~K}$ (right).

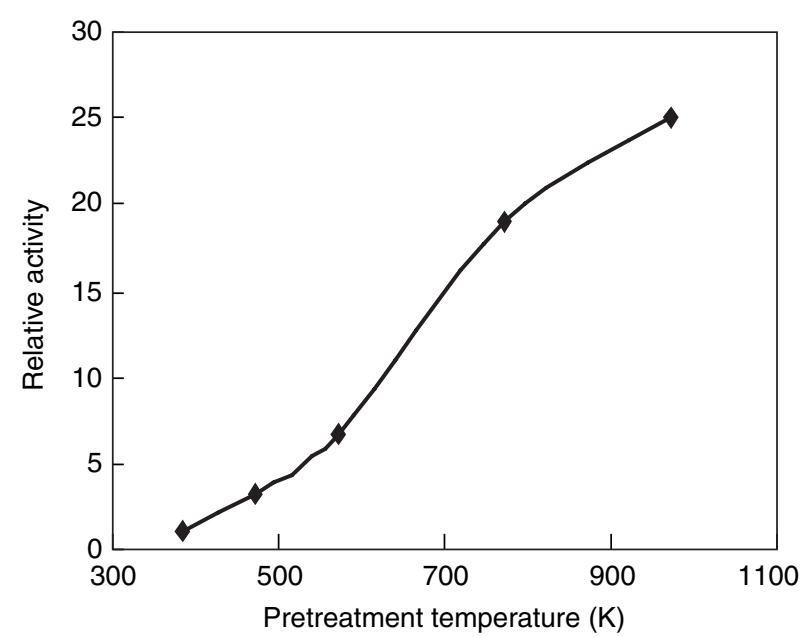

Figure 6

Relative activity of Pt/CNF for hydrogenation of cinnamaldehyde as a function of the treatment temperature in nitrogen.

Extensive characterization using XPS and X-ray absorption studies did not reveal large differences of the electronic properties of the Pt particles upon thermal treatment [23]. The oxygen content of the support, however, strongly decreased with increasing pretreatment temperature as was apparent from both XPS and titration experiments. Based on kinetic modeling, we have proposed a model in which supportassisted adsorption of cinnamaldehyde plays a role to enhance catalyst activity. In Figure 7 a schematic representation [22] of the impact of support oxygen content on the adsorption is given. More specifically, with low oxygen content of the support we propose that the benzene ring of the cinnamaldehyde molecule was adsorbed more strongly thereby facilitating hydrogenation in particular of the $\mathrm{C}=\mathrm{C}$ bond.

Future research will involve the impact of the nature of the carbon nanostructures (fibers, tubes, platelets) and of promoters on these support effects.

\subsection{Other Studies of Carbon Nanofiber Supported Catalysts}

In this section we briefly summarize other studied from our laboratories, mainly by providing the references of earlier papers.

In Fischer Tropsch (FT) catalysis, promoter effects have been studied for $\mathrm{MnO}$ on $\mathrm{Co} / \mathrm{CNF}$. $\mathrm{MnO}$ was introduced by a separate impregnation of manganese nitrate onto $\mathrm{Co} / \mathrm{CNF}$. From STEM-EELS studies it was found that $\mathrm{MnO}$ was only present in the catalyst in association with Co. Accordingly, very low loadings of $\mathrm{MnO}$ were sufficient to achieve considerable effects on the FT catalysis [24].

Most recently, we have studied the effects of cobalt particle sizes (3-30 nm) on FT performance. At 1 bar synthesis gas $\left(\mathrm{H}_{2} / \mathrm{CO}=2 \mathrm{v} / \mathrm{v}\right)$ pressure a clear and sharp optimum for the cobalt-weight based activity at $6 \mathrm{~nm}$ particles has been observed while at 35 bar pressure the optimum is close to $8 \mathrm{~nm}$. This very distinct particle size effect could be studied for the first time without the interference typical of oxide supports [25].

Hydrotalcites (HT) have received increasing attention as solid base catalysts. The lateral size of HT platelets ranges from $60-200 \mathrm{~nm}$ in most catalysis studies. Since the active sites in activated (calcination followed by rehydration) hydrotalcites are located at the edges of the platelets, an 


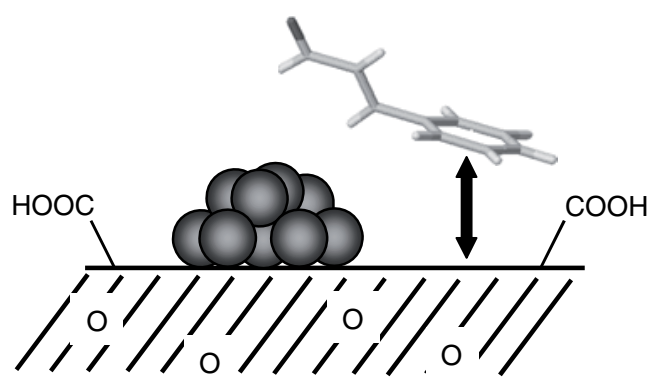

PtCNF

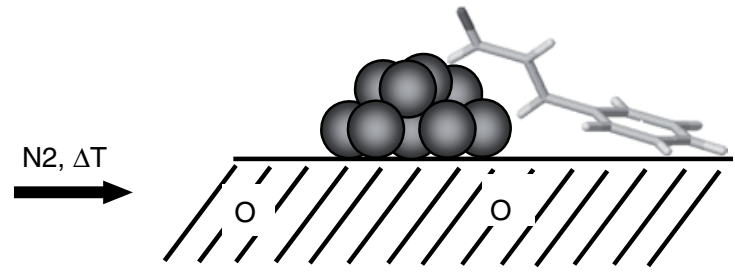

PtCNF973

Figure 7

Effects of support oxygen content on the mode of adsorption of cinnamaldehyde onto Pt/CNF.
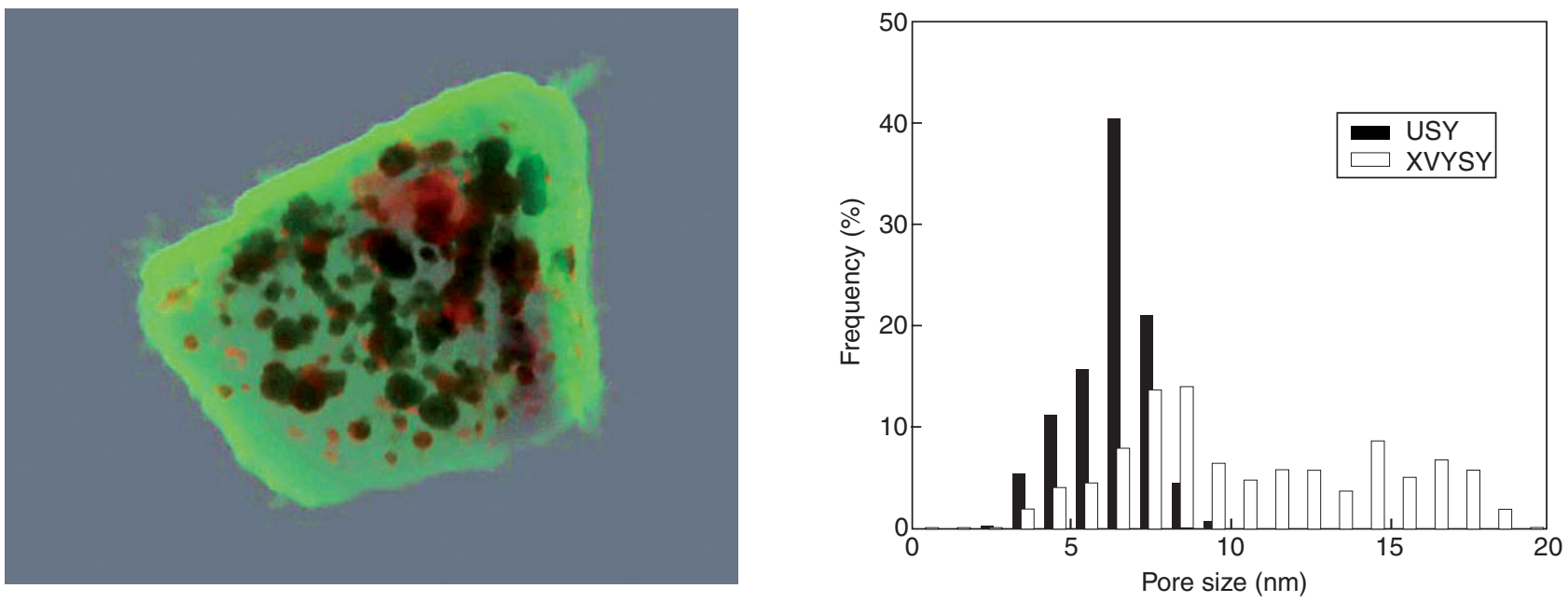

Figure 8

Volume rendering of a crystal of ultra-stabilized zeolite Y (USY) crystal of $\sim 400 \mathrm{~nm}$ size with mesopores of 4-40 nm in the form of cavities and cylinders (left) and the derived pore-size distribution after image binarization (right).

incentive exists to produce platelets of smaller sizes. Recently, we have succeeded to produce HT platelets supported on carbon nanofiber support material. The lateral size typically was around $20 \mathrm{~nm}$ thus leading to a much enhanced weight-based activity compared to bulk HT [26].

Current research on carbon nanofiber and carbon nanotubes focuses also on materials functionalized directly during synthesis. Nitrogen-containing carbon nanotubes, that can be used directly as solid base catalysts, are a case in point.

\section{ELECTRON TOMOGRAPHY}

Conventional TEM suffers from the fact that projection images of a three dimensional object are obtained. In electron tomography, acquisition of a tilt series over sufficiently large angles provides the opportunity to reconstruct the studied object in 3D. Over the last 5 years the first applications to materials science and catalysis have become apparent [27-30]. We summarize some studies and recent work from our laboratory.

\subsection{Mesopores in Stabilized Zeolite Y Crystals}

One of the first systematic studies using electron tomography involved the nature of the mesopores in stabilized zeolite $\mathrm{Y}$ crystals [28]. The nature of the mesopores (diameter 4-40 nm) was reported and compared later on with results from physisorption, mercury intrusion and thermoporometry [31, 32]. 
Most recently we have started to extract quantitative data from the tomograms (Fig. 8). For the mesoporous zeolites pore-size distributions have been obtained that compare quite well with results from nitrogen physisorption [33].

\subsection{Metal Particles and Pore Details in Au/SBA-15}

Using SBA-15 as a nanostructured support material electron tomography of supported gold has been carried out [34]. Volume rendering (Fig. 9) shows the tight fit between the gold particles inside the mesopores and the diameter of those pores (both close to $8 \mathrm{~nm}$ ). Results from physisorption [35] confirmed blockage of the mesopores by the Au particles. Due to the secondary pore system in the walls of SBA-15 [36], however, small molecules such as nitrogen can access and probe the mesopore system.

Recent work on supported metal catalysts has been done to quantify particle sizes with respect to location of the metal particles. The layer thickness of the silica surrounding Pd particles has been assessed quantitatively too [37].

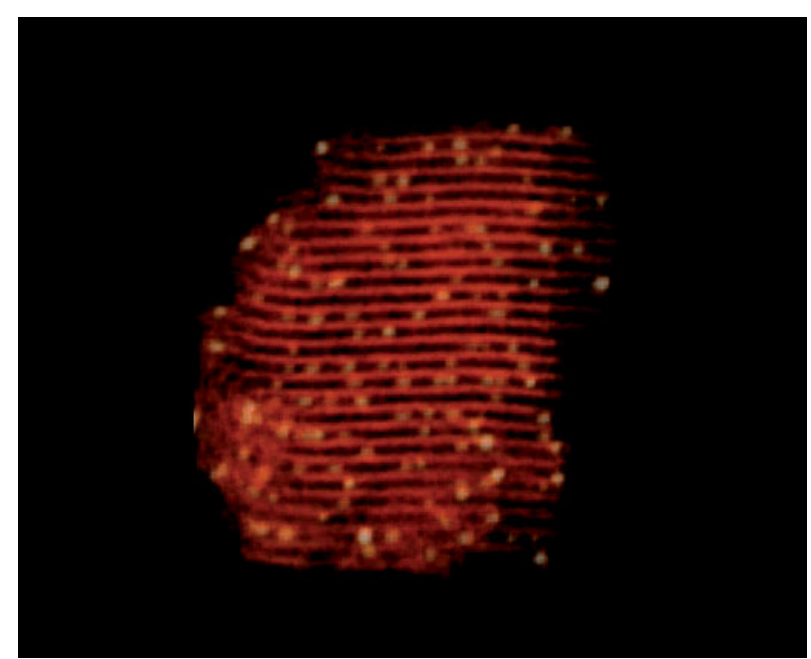

Figure 9

Volume rendering of Au/SBA-15; gold particles yellow, size $8 \mathrm{~nm}$.

\section{CONCLUSIONS}

The advent of nanostructured catalysts has facilitated fundamental studies in catalysis. For example, particle size effects for metal (oxides) can be studied independently from support effects. Electron tomography enables imaging in three dimensions of complex (nano-) structured catalysts.

\section{ACKNOWLEDGEMENTS}

Marjolein Toebes, Martijn van der Lee, Ries Janssen and Ulrike Ziese have made important contributions to the work discussed in this paper. Furthermore, I would like to acknowledge my co-workers Jos van Dillen, Harry Bitter and Petra de Jongh as well as financial support from Utrecht University, NWO/CW, STW and NRSCC.

\section{REFERENCES}

1 A.T. Bell, Science 299 (2003) 1688-1691.

2 J. Grunes, J. Zhu and G.A. Somorjai, Chem. Commun. (2003) 2257-2260.

3 J.S. Beck, J.C. Vartuli, W.J. Roth, M.E. Leonowicz, C.T. Kresge, K.D. Schmitt, C.T.-W. Chu, D.H. Olson, E.W. Sheppard, S.B. McCullen, J.B. Higgins and J.L. Schlenker, J. Am. Chem. Soc. 114 (1992) 10834-10843.

4 D. Zhao, Q. Huo, J. Feng, B.F. Chmelka and G.D. Stucky, J. Am. Chem. Soc. 120 (1998) 6024-6036.

5 K.P. de Jong and J.W. Geus, Catal. Rev. 42 (2000) 481-510.

6 P. Serp, M. Corrias and P. Kalck, Appl. Catal. A-Gen. 253 (2003) 337-358

7 B. Coq, J.M. Planeix and V. Brotons, Appl. Catal. A-Gen. 173 (1998) 175-183.

8 M.J. Ledoux, R. Viera, C. Phan-Huu and N. Keller, J. Catal. 216 (2003) 333-342.

9 M.K. van der Lee, A.J. van Dillen, J.W. Geus, K.P. de Jong and J.H. Bitter, Carbon 44 (2006) 629-637.

10 D.S. Su, N. Maksimova, J. Delgado, N. Séller, G. Mestl, M.-L. Ledoux and R. Schlögl, Catal. Today 110 (2005) 102-103.

11 J.A. Macia-Agullo, D. Cazorla-Amoros, A. Linares-Solano, U. Wild, D.S. Su and R. Schlögl, Catal. Today 248 (2005) 102103.

12 D.S. Su, X.W. Chen, G. Weinberg, A. Klein-Hofmann, O. Timpe, S.B. Abd. Hamid and R. Schlögl, Angew. Chem. Int. Edit. 44 (2005) 5488-5492.

13 W. Xia, D.S. Su, A. Birkner, L. Ruppel, Y. Wang, C. Wöll, J. Qian, C. Liang, G. Marginean, W. Brandl and M. Muhler, Chem. Mater. 17 (2005) 5737-5742.

14 W. Xia, O.F.K. Schluter, C.H. Liang, M.W.E. van den Berg, M. Guraya and M. Muhler, Catal. Today 102 (2005) 34-39.

15 N.B. Jarrah, J.G. van Ommen and L. Lefferts, J. Catal. 239 (2006) 460-469.

16 M.L. Toebes, J.M.P. van Heeswijk, J.H. Bitter, A.J. van Dillen and K.P. de Jong, Carbon 42 (2004) 307-315.

17 M.K. van der Lee, A.J. van Dillen, J.H. Bitter and K.P. de Jong, J. Am. Chem. Soc. 127 (2005) 13573-13582.

18 P. Burattin, M. Che and C. Louis, J. Phys. Chem. B 103 (1999) 6171-6178.

19 P. Burattin, M. Che and C. Louis, J. Phys. Chem. B 104 (2000) 10482-10489.

20 J.H. Bitter, M.K. van der Lee, A.G.T. Slotboom, A.J. van Dillen and K.P. de Jong, Catal. Lett. 89 (2003) 139-142.

21 M.L. Toebes, M.K. van der Lee, L.M. Tang, M.H. Huis in 't Veld, J.H. Bitter, A.J. van Dillen and K.P. de Jong, J. Phys. Chem. B 108 (2004) 11611-11619.

22 M.L. Toebes, T.A. Nijhuis, J. Hájek, J.H. Bitter, J.A. van Dillen, D.Y. Murzin and K.P. de Jong, Chem. Eng. Sci. 60 (2005) 5682-5695 . 
23 M.L. Toebes, Y. Zhang, J. Hájek, T.A. Nijhuis, J.H. Bitter, A.J. van Dillen, D.Y. Murzin, D.C. Koningsberger and K.P. de Jong, J. Catal. 226 (2004) 215-225.

24 G.L. Bezemer, U. Falke, A.J. van Dillen and K.P. de Jong, Chem. Commun. (2005) 731-733.

25 G.L. Bezemer, J.H. Bitter, H.P.C.E. Kuipers, H. Oosterbeek, J.E. Holewijn, X. Xu, F. Kapteijn, A.J. van Dillen and K.P. de Jong, J. Am. Chem. Soc. 128 (2006) 3956-3964.

26 F. Winter, A.J. van Dillen and K.P. de Jong, Chem. Commun. (2005) 3977-3979.

27 A.J. Koster, U. Ziese, A.J. Verkleij, A.H. Janssen and K.P. de Jong, J. Phys. Chem. B 104 (2000) 9368-9370.

28 A.H. Janssen, A.J. Koster and K.P. de Jong, Angew. Chem. Int. Edit. 40 (2001) 1102-1104.

29 P.A. Midgley, M. Weyland, J.M. Thomas and B.F.G. Johnson, Chem. Commun. (2001) 907-908.

30 I. Arslan, T.J.V. Yates, N.D. Browning and P.A. Midgley, Science 309 (2005) 2195-2198.
31 A.H. Janssen, A.J. Koster and K.P. de Jong, J. Phys. Chem. B 106 (2002) 11905-11909.

32 A.H. Janssen, H. Talsma, M.J. van Steenbergen and K.P. de Jong, Langmuir 20 (2004) 41-45.

33 U. Ziese, C.J. Gommes, S. Blacher, A.H. Janssen, A.J. Koster and K.P. de Jong, Stud. Surf. Sci. Catal. 158 (2005) 633-638.

34 U. Ziese, K.P. de Jong and A.J. Koster, Appl. Catal. A-Gen. 260 (2004) 71-74.

35 A.H. Janssen, C.-M. Yang, Y. Wang, F. Schüth, A.J. Koster and K.P. de Jong, J. Phys. Chem. B. 107 (2003) 10552-10556.

36 K.P. de Jong, A.J. Koster, A.H. Janssen and U. Ziese, Stud. Surf. Sci. Catal. 157 (2005) 225-242.

37 C.J. Gommes, K.P. de Jong, J.-P. Pirard and S. Blacher, Langmuir 21 (2005) 12378-12385.

Final manuscript received in June 2006

Copyright $(\mathbb{C} 2006$ Institut français du pétrole

Permission to make digital or hard copies of part or all of this work for personal or classroom use is granted without fee provided that copies are not made or distributed for profit or commercial advantage and that copies bear this notice and the full citation on the first page. Copyrights for components of this work owned by others than IFP must be honored. Abstracting with credit is permitted. To copy otherwise, to republish, to post on servers, or to redistribute to lists, requires prior specific permission and/or a fee: Request permission from Documentation, Institut français du pétrole, fax. +33147527078 , or revueogst@ifp.fr. 